\title{
Effects of ATP-binding cassette transporter G2 in extracellular vesicles on drug resistance of laryngeal cancer cells in in vivo and in vitro
}

\author{
YAN ZHAO ${ }^{1}$, YUETONG CHEN ${ }^{2}$, JING WANG ${ }^{2}$ and LIANG LIU ${ }^{2}$ \\ ${ }^{1}$ Department of Otolaryngology, Head and Neck Surgery; ${ }^{2}$ Tumor Institute, \\ The Fourth Hospital of Hebei Medical University, Shijiazhuang, Hebei 050011, P.R. China \\ Received September 1, 2020; Accepted February 16, 2021
}

DOI: $10.3892 / \mathrm{ol} .2021 .12625$

\begin{abstract}
Drug resistance is one of the main factors limiting the efficacy of chemotherapy in patients with laryngeal cancer; thus, it is important to investigate the drug resistance of laryngeal cancer. In the present study, the mechanism of the regulation of drug resistance in laryngeal cancer cells by ATP-binding transporter G2 (ABCG2) that is present in the extracellular vesicles (EVs) released by drug-resistant cells was studied in vivo and in vitro. A cisplatin (CDDP)resistant cell line (AMC-HN-8/CDDP) was established from AMC-HN-8 cells by continuous exposure to increasing concentrations of CDDP. The EVs extracted from the culture medium of AMC-HN-8/CDDP and AMC-HN-8 cells were termed EVs1 and EVs2, respectively. Following 48-h treatment of AMC-HN-8 cells with EVs1 or EVs2, the cells were designated as AMC-HN-8-EVs1 or AMC-HN-8-EVs2. Nude mice bearing AMC-HN-8-EVs1 and AMC-HN-8 cell-derived xenograft tumors were established to detect the effects of EVs on drug resistance. The resistance index of AMC-HN-8/ CDDP cells to CDDP was 5.60, which was determined by the MTT assay. The mRNA and protein expression levels of ABCG2 in AMC-HN-8/CDDP cells and EVs1 were significantly higher compared with those in AMC-HN-8 cells and EVs2, respectively $(\mathrm{P}<0.01)$. The $\mathrm{ABCG} 2 \mathrm{mRNA}$ and protein levels, and the proliferation index of AMC-HN-8-EVs1 cells were significantly higher compared with those of AMC-HN8 -EVs2 and AMC-HN-8 cells $(\mathrm{P}<0.01)$, whereas the apoptotic rate was significantly lower $(\mathrm{P}<0.01)$. The mean volume of subcutaneous tumor xenografts in the test group (inoculated with AMC-HN-8-EVs1 cells and intraperitoneally injected with $3 \mathrm{mg} / \mathrm{kg}$ CDDP) was significantly higher compared
\end{abstract}

Correspondence to: Professor Liang Liu, Tumor Institute, The Fourth Hospital of Hebei Medical University, 12 Jiankang Road, Shijiazhuang, Hebei 050011, P.R. China

E-mail: aliangdaziran@163.com

Key words: laryngeal carcinoma, drug resistance, extracellular vesicles, ATP-binding cassette transporter G2, animal experiment with that in the control group (inoculated with AMC-HN-8 cells and intraperitoneally injected with $3 \mathrm{mg} / \mathrm{kg}$ CDDP) $(\mathrm{P}<0.01)$, whereas the apoptotic rate of tumor cells was significantly lower $(\mathrm{P}<0.01)$. The ABCG2 mRNA and the protein expression levels in the tumor cells of the test group were significantly higher compared with those in the blank (inoculated with AMC-HN-8 cells and was intraperitoneally injected with normal saline) and control groups $(\mathrm{P}<0.01)$. The high expression levels of ABCG2 in laryngeal carcinoma cells affected the drug resistance of the cells. The EVs released by drug-resistant cells upregulated the expression of ABCG2 and induced drug resistance in laryngeal carcinoma cells, which may be dependent on the ABCG2 gene carried by the EVs.

\section{Introduction}

Laryngeal carcinoma is a common malignant tumor of the head and neck with high incidence and mortality rates, which severely threatens the patients' life and health. He et al (1) have reported that age-standardized incidence rates of laryngeal carcinoma by Chinese standard population and by world standard population were 1.18 and 1.19 per 100,000 individuals, respectively, and age-standardized mortality rates by Chinese standard population and by world standard population were 0.61 and 0.61 per 100,000 individuals, respectively, in China in 2015. The conventional treatment options for laryngeal cancer include surgery $(2,3)$, radiotherapy $(4,5)$, chemotherapy $(6,7)$ and biotherapy (8).

Chemotherapy is the main treatment approach for patients with advanced and postoperative recurrent laryngeal cancer (9). Cisplatin (CDDP) is often used as a chemotherapeutic drug for laryngeal cancer, and anticancer effects have been observed in a number of patients with laryngeal cancer undergoing chemotherapy with CDDP. However, drug resistance is one of the main factors limiting the efficacy of chemotherapy in patients with laryngeal cancer $(10,11)$.

The increase in cell membrane transporter expression has been demonstrated to be associated with the drug resistance of tumors, among which the ATP binding-cassette (ABC) proteins are the major factors (12). ABCB1 and ABCG2 are members of the ABC superfamily and are implicated in drug resistance (13-16). 
Our previous studies have established cell (17) and animal (18) esophageal cancer models with Adriamycin resistance, in which the association between ABCG2 expression and Adriamycin resistance of esophageal squamous cell carcinoma has been demonstrated. In vitro and in vivo experiments have confirmed the involvement of ABCG2 in esophageal cancer drug resistance $(17,18)$. Based on these results, the present study aimed to determine relationship between ABCG2 and drug resistance of laryngeal squamous cell carcinoma. ABCG2 has been demonstrated to be expressed at high levels in various types of tumor, such as esophageal, ovarian and breast cancer, as well as osteosarcoma, and to participate in the development of drug resistance in tumor cells (18-22); however, a limited number of reports are currently available on the effects of ABCG2 in laryngeal squamous cell carcinoma (23). In addition, the mechanism by which drug-resistant cells affect the drug resistance of neighboring cells has not been elucidated to date.

Tumor microenvironment serves an important role in tumor development, drug resistance and cancer therapy $(24,25)$. Tumor cells create a favorable microenvironment for tumor development by transferring the information (DNA, RNA and protein) between cells, which promotes tumor development $(26,27)$. Therefore, investigating the mechanism of acquired drug resistance caused by changes in the tumor microenvironment provides a new direction for studying drug resistance in laryngeal squamous cell carcinoma.

Extracellular vesicles (EVs) are supermicrocystic structures that are produced and released by both tumor and normal cells (28). EVs are bioactive substances that are secreted by cells and include microvesicles (MVs) and exosomes $(29,30)$. During the formation of EVs, proteins, mRNAs and noncoding RNAs are functionally selected from the source cells; these signaling molecules are released into the target cells during interaction between EVs and target cells, serving a functional role by changing the genotype and phenotype of the target cells $(31,32)$.

A limited number of studies have reported that EVs released by certain types of tumor cells, such as prostate and lung cancer cells, can promote cell proliferation, tumor angiogenesis, metastasis and immune escape by acting on tumor cells, endothelial cells, tumor-related fibroblasts and immune cells in their microenvironment, thus promoting the occurrence and development of tumors $(33,34)$. Takahashi et al (35) have confirmed that the exosomes secreted by hepatocellular carcinoma cells regulate the biological activity of target cells through their intrinsic microRNAs and suggested that long non-coding (lnc)RNAs are also present in EVs. For example, IncRNA very low-density lipoprotein receptor in EVs has been demonstrated to regulate acquired drug resistance of hepatocellular carcinoma cells by acting on ABCG2.

The present study aimed to study the regulatory effects of EVs released by drug-resistant laryngeal cancer cells on cell drug resistance, providing a new method for investigating the drug resistance mechanism in laryngeal cancer.

\section{Materials and methods}

Cell lines. Human laryngeal cancer cells AMC-HN-8 were purchased from Beijing Bnbio Co., Ltd. The AMC-HN-8 cells were cultured in DMEM (Gibco; Thermo Fisher Scientific, Inc.) containing $10 \%$ fetal bovine serum (FBS; Gibco; Thermo Fisher Scientific, Inc.) and $100 \mathrm{U} / \mathrm{l}$ of penicillin and streptomycin (North China Pharmaceutical Co., Ltd.) in a humidified atmosphere containing $5 \% \mathrm{CO}_{2} / 95 \%$ air at $37^{\circ} \mathrm{C}$. A CDDP resistant cell line was established from AMC-HN-8 cells by continuously exposing the cells to increasing concentrations of CDDP $(0.01-2 \mu \mathrm{g} / \mathrm{ml})$ for 8 months. At the end of the exposure, one of the surviving clones was isolated and designated as AMC-HN-8/CDDP, and was further maintained in medium containing $2 \mu \mathrm{g} / \mathrm{ml} \mathrm{CDDP}$.

MTT assay and inhibitory rate calculation. The monolayer of cultured AMC-HN-8, AMC-HN-8/CDDP, AMC-HN-8-EVs1 and AMC-HN-8-EVs2 cells was digested by $0.25 \%$ trypsin, and DMEM with $10 \%$ FBS was added to the mixture to produce a single-cell suspension. The cell density was adjusted to $1 \times 10^{4}$ cells $/ \mathrm{ml}$, and the cells were inoculated into a 96-well plate and cultured at $37^{\circ} \mathrm{C}$ with $5 \% \mathrm{CO}_{2}$ in order to achieve adherence. After $24 \mathrm{~h}$, once the cells firmly adhered to the plate, various concentrations of $\operatorname{CDDP}(0,0.05,0.1,0.2,0.5,1,2,5$, 10,20 and $50 \mu \mathrm{g} / \mathrm{ml}$ ) were added. The total reaction volume was $200 \mu \mathrm{l} / \mathrm{well}$. The cells in the negative control group were incubated with the medium. In the wells of the blank control group, only the medium was present. The reactions for each CDDP concentration, the negative and blank control groups were repeated in three wells. Following $24-\mathrm{h}$ culture at $37^{\circ} \mathrm{C}$ with $5 \% \mathrm{CO}_{2}, 20 \mu \mathrm{l}$ MTT solution $(5 \mathrm{mg} / \mathrm{ml}$; Sigma-Aldrich; Merck $\mathrm{KGaA}$ ) was added to each well and incubated for another $4 \mathrm{~h}$. Subsequently, the solution was replaced with $180 \mu \mathrm{l} /$ well DMSO, and the plates were agitated for $10 \mathrm{~min}$. The blank control value was set as 0 , and the optical density of each well was read at $490 \mathrm{~nm}$ using a microplate spectrophotometer. The inhibitory rate (IR) was calculated by the following formula in order to calculate the $50 \%$ inhibitory concentration $\left(\mathrm{IC}_{50}\right)$ of the cells: IR $(\%)=(1-$ Test group A490/Control group A490) $\mathrm{x}$ $100 \%$. The resistance index was determined as the $\mathrm{IC}_{50}$ of the resistant cells/the $\mathrm{IC}_{50}$ of the parental cells.

Xenograft assay. BALB/c nude mice (age, 5-7 weeks; weight, 19-23 g) were obtained from Beijing Vital River Laboratory Animal Technology Co., Ltd., China. A total of 18 mice ( 9 male and 9 female) were equally divided into three groups ( $\mathrm{n}=6 ; 3$ male and 3 female per group) according to their body weight. The mice were housed in a controlled environment with a temperature of $25 \pm 1^{\circ} \mathrm{C}$, relative humidity of $40-60 \%$, a light/dark cycle of $12 / 12 \mathrm{~h}$ and free access to a standard diet and water. The mice were subcutaneously injected with $200 \mu \mathrm{l}$ cancer cell suspension containing $6 \times 10^{6}$ AMC-HN-8 or AMC-HN-8-EVs1 cells at the right forelimb. At 5 days, the tumor formation rate was $100 \%$. The treatment groups were as follows: i) The blank control group was inoculated with AMC-HN-8 cells and was intraperitoneally injected with normal saline (NS); ii) the control group was inoculated with AMC-HN-8 cells and intraperitoneally injected with $3 \mathrm{mg} / \mathrm{kg}$ CDDP; and iii) the test group was inoculated with AMC-HN8-EVs1 cells and intraperitoneally injected with $3 \mathrm{mg} / \mathrm{kg}$ CDDP. CDDP was injected once every 7 days, and the total duration of the treatment was 2 weeks. The volume of the tumors was calculated as follows: $\mathrm{V}=\mathrm{ax} \mathrm{b}^{2} / 2$, where $\mathrm{a}$ and $\mathrm{b}$ represent the 
long and short diameter of the tumor, respectively. Mice were sacrificed by cervical dislocation at the end of the treatment period; death was confirmed by the sound of cervical spine fracture and the absence of breathing. All animal experiments were performed in compliance with the regulations and guidelines of The Fourth Hospital of Hebei Medical University institutional animal care and according to the AAALAC and IACUC guidelines. The Ethics Committee of the Fourth Hospital of Hebei Medical University (Shijiazhuang, China) approved this study (approval no. 2018MEC106).

Subcutaneous tumor single cell suspension. After dissection of the subcutaneous tumors, single cell suspension was immediately prepared using the mesh rubbing method, and the cell density was adjusted to $1 \times 10^{7}$ cells $/ \mathrm{ml}$. The main steps of mesh rubbing method were as follows: Tumor tissue was placed on a 150-mesh sieve and washed with PBS for three times. A dish was placed under the sieve, and ophthalmic scissors were used to cut the tissues. Ophthalmic tweezers were used to lightly rub the tissue. Samples were then rinsed with PBS and passed through a 300-mesh nylon sieve, and the cell suspension was collected.

Reverse transcription-quantitative $(R T-q) P C R$. The RNA Isolater (Vazyme Biotech Co., Ltd.) was used to extract the total RNA from AMC-HN-8, AMC-HN-8/CDDP, AMC-HN-8-EVs1, AMC-HN-8-EVs2 cells and EVs. For mouse subcutaneous tumor analysis, $50 \mathrm{mg}$ of tumor tissue was sampled, washed with precooled PBS twice and mixed with $1 \mathrm{ml}$ RNA Isolater solution; the total RNA was extracted according to routine one-step assay (36). The cDNA was synthesized using the HiScript II First Strand cDNA Synthesis kit (Vazyme Biotech Co., Ltd) according to the manufacturer's protocol. Human GAPDH was used as an internal reference. SYBR ${ }^{\circledR}$ Green I (Vazyme Biotech Co., Ltd.) was used as fluorescent dye. qPCR was using the SYBR Green Master Mix kit (Vazyme Biotech Co., Ltd.) according to the manufacturer's protocol. The thermocycling conditions were as follows: $95^{\circ} \mathrm{C}$ for $5 \mathrm{~min}$ (pre-denaturation), followed by 40 cycles at $95^{\circ} \mathrm{C}$ for $10 \mathrm{sec}$ and $60^{\circ} \mathrm{C}$ for $30 \mathrm{sec}$, and dissociation at $95^{\circ} \mathrm{C}$ for $15 \mathrm{sec}, 60^{\circ} \mathrm{C}$ for $1 \mathrm{~min}$ and $95^{\circ} \mathrm{C}$ for $15 \mathrm{sec}$. The experiments for each sample were repeated thrice. The primers used were as follows: ABCG2 forward, 5'-GGTCAGAGTGTGGTTTCTGTAGCA-3' and reverse, 5'-GTGAGAGATCGATGCCCTGCTTTA-3'; and GAPDH forward, 5'-ACCACAGTCCATGCCATCAC-3' and reverse, 5'-TCCACCACCCTGTTGCTGTA-3'. The relative expression levels of ABCG2 mRNA were calculated using the $2^{-\triangle A C q}$ method (37).

Protein expression analysis by flow cytometry (FCM). The AMC-HN-8, AMC-HN-8/CDDP, AMC-HN-8-EVs1 and AMC-HN-8-EVs2 cells were collected and washed with cold phosphate-buffered saline (PBS) twice. A volume of $0.1 \mathrm{ml}$ single cell suspension (containing $1 \times 10^{6}$ cells) was incubated with $10 \mu 1$ FITC-labeled ABCG2 antibody (undiluted; cat. no. 332014; Biolegend, Inc.) in the dark for $30 \mathrm{~min}$ at room temperature. In addition, $0.1 \mathrm{ml}$ subcutaneous tumor single cell suspension was prepared as aforementioned and incubated with $10 \mu \mathrm{l}$ FITC-labeled ABCG2 antibody (undiluted) in the dark for $30 \mathrm{~min}$ at room temperature. The cells were washed with PBS, and the protein expression levels were determined using an FC-500 type flow cytometer (Beckman Coulter, Inc.). Immunofluorescence data was measured using the EXPO 32 ADC v1.2 software (Beckman Coulter, Inc.). The protein expression level was expressed as the mean fluorescence intensity.

EV extraction from AMC-HN-8 and AMC-HN-8/CDDP cell culture medium. The AMC-HN-8 and AMC-HN-8/ CDDP cells were cultured for $48 \mathrm{~h}$ until they reached the logarithmic phase. The EVs were collected from the medium of the AMC-HN-8/CDDP and AMC-HN-8 cells via gradient centrifugation and were termed EVs1 and EVs2, respectively. The EVs were collected by the following steps: i) Supernatant was obtained by gradient centrifugation $(600 \mathrm{x} \mathrm{g}, 10 \mathrm{~min}$; $1,500 \mathrm{x} \mathrm{g}, 30 \mathrm{~min} ; 10,000 \mathrm{xg}, 1 \mathrm{~h})$ at $4^{\circ} \mathrm{C}$; ii) this supernatant was centrifuged at $110,000 \mathrm{x}$ g for $16 \mathrm{~h}$ at $4^{\circ} \mathrm{C}$; iii) the supernatant was discarded, and the deposit of EVs was obtained by dissolving it in PBS at $4^{\circ} \mathrm{C}$; and iv) the EVs were quantified by Nanodrop (Thermo Fisher Scientific, Inc.).

AMC-HN-8 cell incubation with EVs. The AMC-HN-8 cells were collected by trypsin digestion. The density of the cell suspension was adjusted to $1 \times 10^{5}$ cells $/ \mathrm{ml}$, and $3 \mathrm{ml}$ cell suspension was seeded into 6-well culture plates in triplicate. The cell groups were treated with $50 \mu 1 \mathrm{EVs} 1, \mathrm{EVs} 2$ or normal saline; following 48-h treatment of AMC-HN-8 cells with $\mathrm{EVs} 1$ and EVs2 at $37^{\circ} \mathrm{C}$ with $5 \% \mathrm{CO}_{2}$, the cells were termed AMC-HN-8-EVs1 and AMC-HN-8-EVs2 cells, respectively, and the saline-treated group was used as the control. The concentration of all EV solutions was $50 \mu \mathrm{g} / \mathrm{ml}$. Following treatment, the density of the single-cell suspension was adjusted to $1 \times 10^{6}$ cells $/ \mathrm{ml}$.

Cell cycle assay. A total of $1 \mathrm{ml}$ single-cell suspension was collected from each group following treatment with EVs. The cells were washed with ice-cold PBS and fixed with $70 \%$ alcohol at $4^{\circ} \mathrm{C}$ for $24 \mathrm{~h}$. Following washing twice with ice-cold PBS, the cells were suspended in $100 \mu \mathrm{l}$ PBS, and $1 \mathrm{ml}$ propidium iodide (BD Biosciences) was added to the suspension for staining at $4^{\circ} \mathrm{C}$ for 30 min prior to cell cycle detection with an FC-500 type flow cytometer (Beckman Coulter, Inc.). The data were analyzed using the Multicycle AV software version 275 (Phoenix Flow Systems, Inc.). The proliferation index (PI) was calculated using the following formula: $P I=\left(S+G_{2} / M\right) /\left(G_{0 / 1}\right.$ $\left.+\mathrm{S}+\mathrm{G}_{2} / \mathrm{M}\right) \times 100 \%$.

Apoptosis assay. A total of $1 \mathrm{ml}$ single-cell suspension from each AMC-HN-8 cell group following treatment with EVs or $0.1 \mathrm{ml}$ subcutaneous tumor single-cell suspension was collected and resuspended in $100 \mu \mathrm{l}$ PBS. The cells were washed with ice-cold PBS and suspended in $100 \mu 1 \mathrm{IX}$ binding buffer (BD Biosciences). Subsequently, $10 \mu \mathrm{l}$ of Annexin V-FITC (BD Biosciences) was added, and the mixture was placed on ice for $15 \mathrm{~min}$ in the dark prior to the addition of $380 \mu \mathrm{l} 1 \mathrm{X}$ binding buffer and $10 \mu \mathrm{l}$ propidium iodide. The cells were incubated on ice for $15 \mathrm{~min}$ in the dark, washed once with cold PBS, resuspended in $1 \mathrm{ml}$ PBS and analyzed using a FC-500 type flow cytometer (Beckman Coulter, Inc.). Early 
A

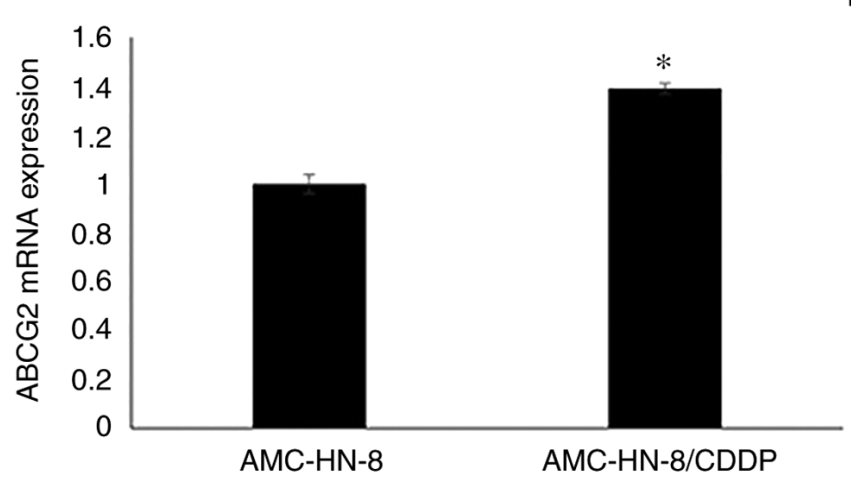

B

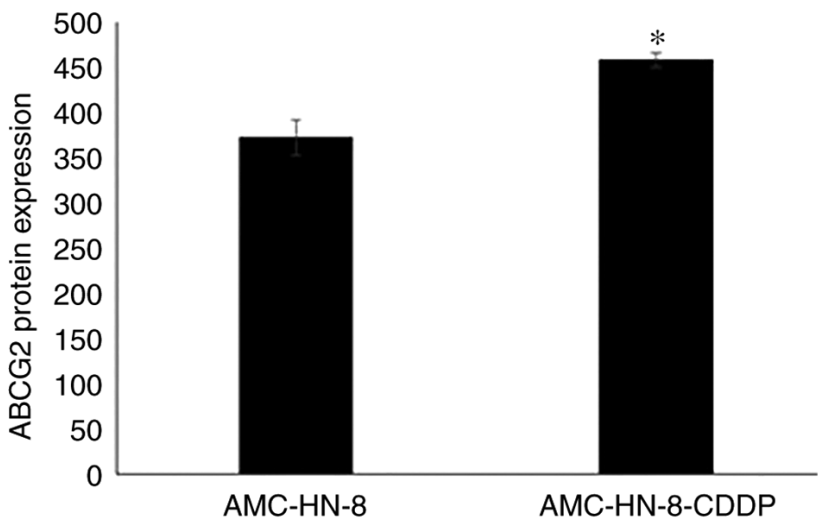

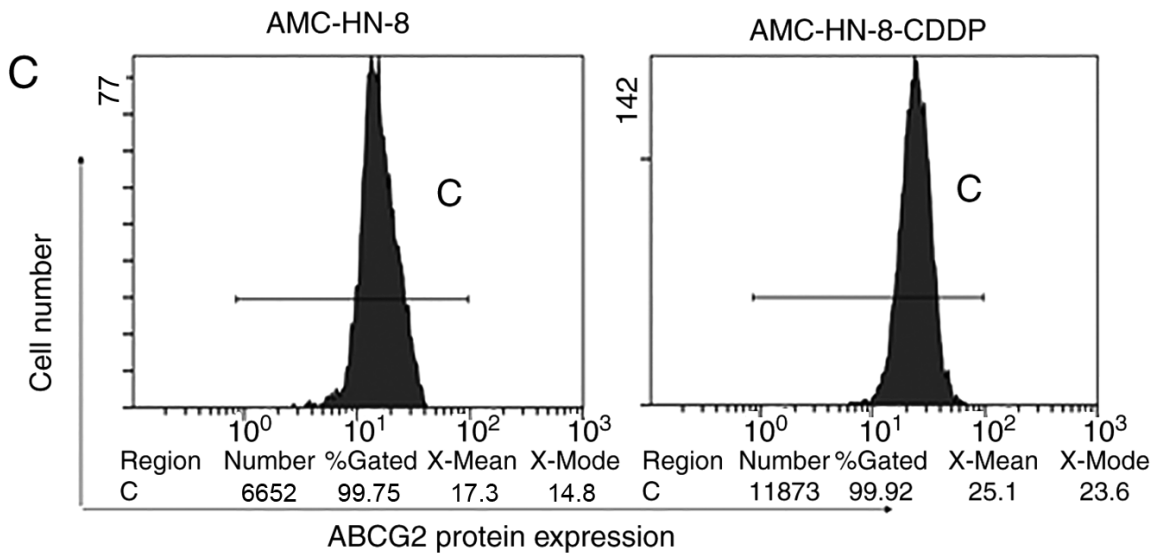

Figure 1. ABCG2 gene and protein expression levels in AMC-HN-8 and AMC-HN-8/CDDP cells. (A) ABCG2 mRNA expression levels in AMC-HN-8 and AMC-HN-8/CDDP cells were detected by reverse transcription-quantitative PCR. The ABCG2 mRNA expression levels in AMC-HN-8/CDDP cells were significantly higher compared with those in AMC-HN-8 cells. (B and C) ABCG2 protein expression levels in AMC-HN-8 and AMC-HN-8/CDDP cells were detected by flow cytometry. ABCG2 protein expression levels in AMC-HN-8/CDDP cells were significantly higher compared with those in AMC-HN-8 cells. ${ }^{*} \mathrm{P}<0.01$ vs. AMC-HN-8. ABCG2, ATP-binding transporter G2; CDDP, cisplatin.

and late apoptotic cells were assessed. The apoptotic rate was measured using the EXPO 32 ADC v1.2 software (Beckman Coulter, Inc.).

Statistical analysis. Statistical analysis was performed using SPSS 21 software (IBM Corp.). Data are presented as the mean \pm standard deviation. Multi-group comparisons were performed by one-way ANOVA followed by Tukey's post hoc test. $\mathrm{P}<0.05$ was considered to indicate a statistically significant difference.

\section{Results}

Establishment of drug-resistant laryngeal cancer cells and the drug-resistant phenotype of AMC-HN-8/CDDP cells. Following 24-h treatment with CDDP, the $\mathrm{IC}_{50}$ of CDDP in AMC-HN-8 cells was detected by MTT method. The $\mathrm{IC}_{50}$ of CDDP in AMC-HN-8 cells was $6.47 \pm 0.16 \mu \mathrm{g} / \mathrm{ml}$ (data not shown). Based on the $\mathrm{IC}_{50}$ value, the CDDP concentrations ranging between 0.01 and $2 \mu \mathrm{g} / \mathrm{ml}$ were used to treat the AMC-HN-8 cells in order to establish the drug-resistant cell line AMC-HN-8/CDDP.

The AMC-HN-8/CDDP cell line was successfully established from the parental CDDP-sensitive cell line AMC-HN-8 by continuous exposure to increasing concentrations of CDDP for 8 months. One of the surviving clones was isolated and termed AMC-HN-8/CDDP. The $\mathrm{IC}_{50}$ value of CDDP in the AMC-HN-8/CDDP cells was $36.22 \pm 1.62 \mu \mathrm{g} / \mathrm{ml}$. The resistance index of AMC-HN-8/CDDP cells to CDDP was 5.60 (data not shown).

The ABCG2 gene and the protein expression levels in AMC-HN-8 and AMC-HN-8/CDDP cells were detected by RT-qPCR and FCM. The results revealed that the ABCG2 mRNA and protein expression levels in AMC-HN-8/CDDP cells were significantly higher compared with those in AMC-HN-8 cells $(\mathrm{P}<0.01$; Fig. 1$)$. The expression trends of the protein and mRNA levels in these cells were consistent.

Drug-resistant phenotype of AMC-HN-8 cells is modulated by EVs in vitro. The ABCG2 mRNA expression in EVs was detected by RT-qPCR, and the results revealed that the ABCG2 mRNA expression levels in EVs1 derived from drug-resistant AMC-HN-8/CDDP cells were significantly higher compared with those in EVs2 derived from the parental CDDP-sensitive AMC-HN-8 cells ( $\mathrm{P}<0.01$; Fig. $2 \mathrm{~A})$.

Following 48-h treatment with EVs and 24-h exposure to CDDP, the $\mathrm{IC}_{50}$ value of AMC-HN-8 cells was detected by the MTT method. As presented in Fig. $2 \mathrm{~B}$, the $\mathrm{IC}_{50}$ value in the AMC-HN-8-EVs1 group was significantly higher compared with those in the AMC-HN-8-EVs2 and AMC-HN-8 groups $(\mathrm{P}<0.01$; Fig. 2B). No significant differences were observed between the $\mathrm{IC}_{50}$ values in the AMC-HN-8-EVs2 and the 
A

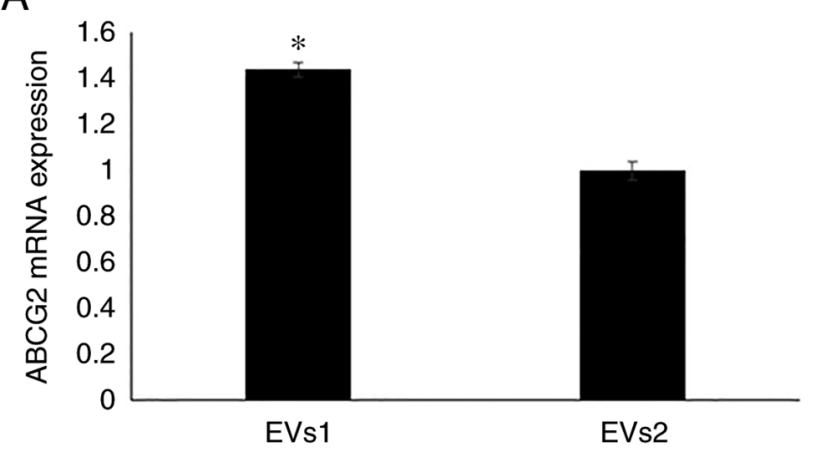

C

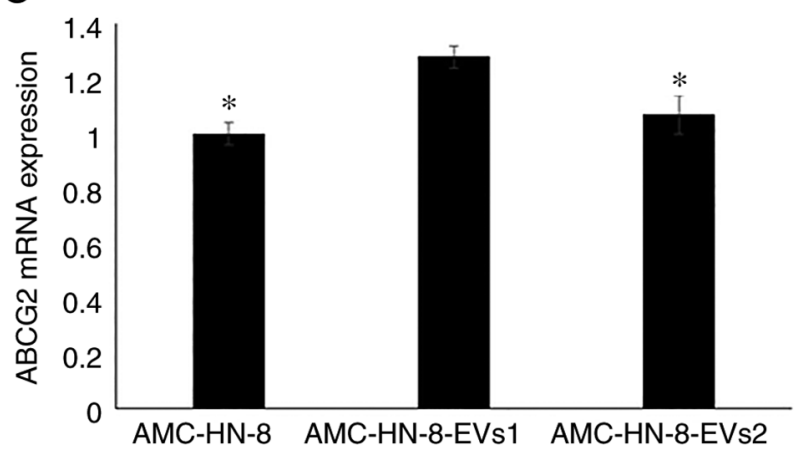

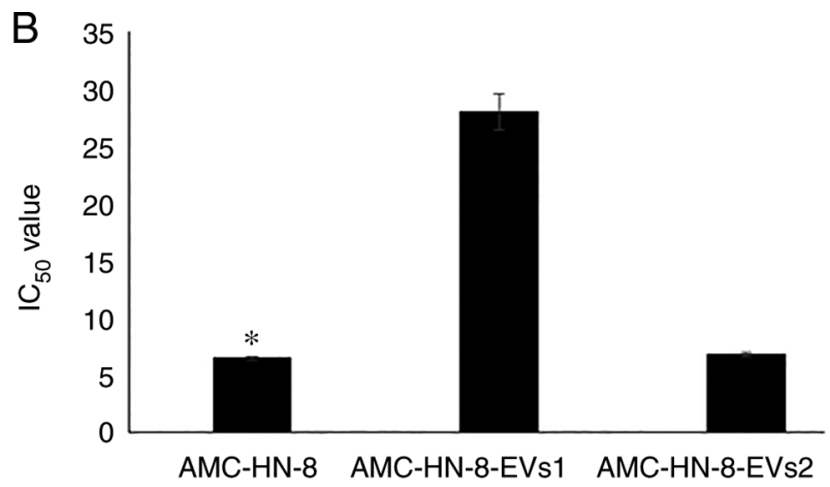

D

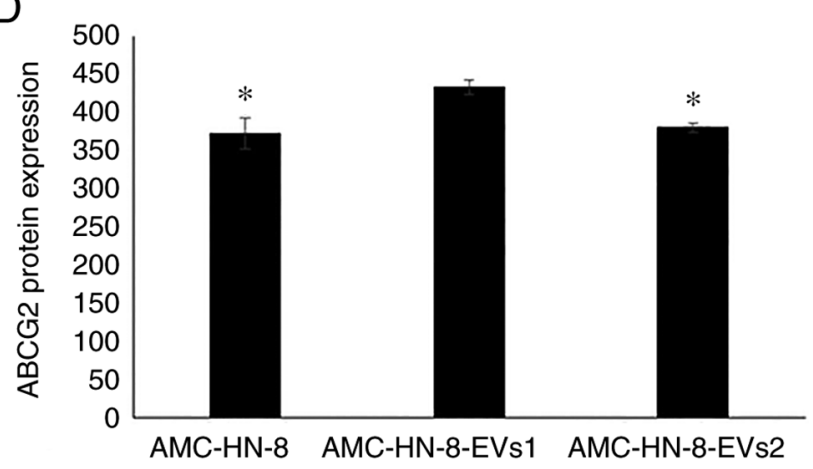

$\mathrm{E}$
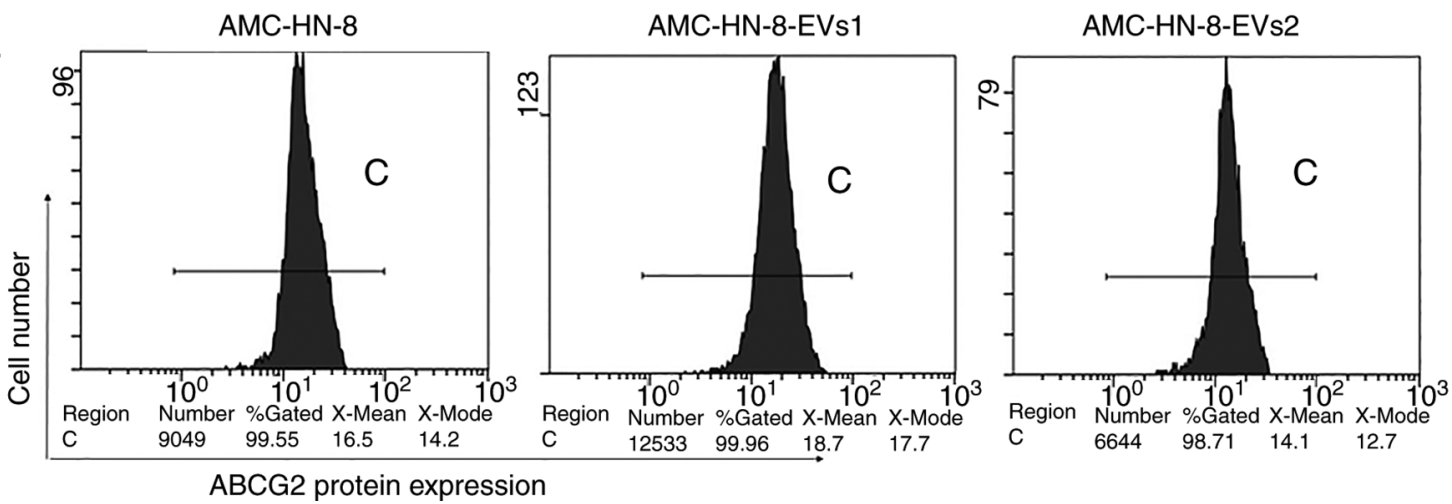

Figure 2. Drug-resistant phenotype of AMC-HN-8 cells is modulated by EVs in vitro. (A) ABCG2 mRNA expression levels in EVs were detected by RT-qPCR ABCG2 mRNA expression levels in EVs1 were significantly higher compared with those in EVs2. "P<0.01 vs. EVs2. (B) $\mathrm{IC}_{50}$ value of CDDP in AMC-HN-8 cells following treatment with EVs. The $\mathrm{IC}_{50}$ value of CDDP on AMC-HN-8 cells was significantly higher following treatment with EVs1 compared with that in cells treated with EVs2. "P<0.01 vs. AMC-HN-8-EVs1. (C-E) The mRNA and protein expression levels of ABCG2 in AMC-HN-8 cells following treatment with EVs. (C) ABCG2 mRNA expression levels in cells were detected by RT-qPCR. ABCG2 mRNA expression levels in the AMC-HN-8-EVs1 group were significantly higher compared with those in AMC-HN-8-EVs2 and AMC-HN-8 control groups. "P<0.01 vs. AMC-HN-8-EVs1. (D) ABCG2 protein expression levels in the AMC-HN-8-EVs1 group were significantly higher compared with those in the AMC-HN-8-EVs2 and AMC-HN-8 control groups. "P<0.01 vs. AMC-HN-8-EVs1. (E) Representative flow cytometry plots of ABCG2 protein expression in AMC-HN-8 cells. ABCG2, ATP-binding transporter G2; CDDP, cisplatin; EVs, extracellular vehicles; EVs1, EVs derived from AMC-HN-8/CDDP cells; EVs2, EVs derived from AMC-HN-8 cells; RT-qPCR, reverse transcription-quantitative PCR.

AMC-HN-8 control groups (P>0.05; Fig. 2B). The resistance index of AMC-HN-8-EVs1 cells to CDDP was 4.32 (data not shown).

Following 48-h treatment with EVs, the ABCG2 gene and protein expression levels in AMC-HN-8 cells were detected by RT-qPCR and FCM, respectively. The ABCG2 mRNA and protein expression levels in the AMC-HN-8-EVs1 group were significantly higher compared with those in the AMC-HN8-EVs2 and AMC-HN-8 control groups ( $\mathrm{P}<0.01$; Fig. 2C-E). The ABCG2 mRNA and protein expression levels in EVs2 group exhibited no significant differences compared with those in the control group ( $\mathrm{P}>0.05$; Fig. 2C-E). Therefore, the $\mathrm{ABCG} 2$ expression levels were increased following treatment with EVs1 derived from drug-resistant AMC-HN-8/CDDP cells.

EVs modulate the cell cycle and apoptotic rate of AMC-HN-8 cells. The changes in the cell cycle distribution in AMC-HN-8 cells treated with EVs were determined by flow cytometry. In the $G_{0 / 1}$ and $G_{2} / M$ phases of the cell cycle, the percentages of cells in the EVs1 group were lower compared with those in the EVs2 and control groups $(\mathrm{P}<0.01)$; the EVs2 group exhibited 

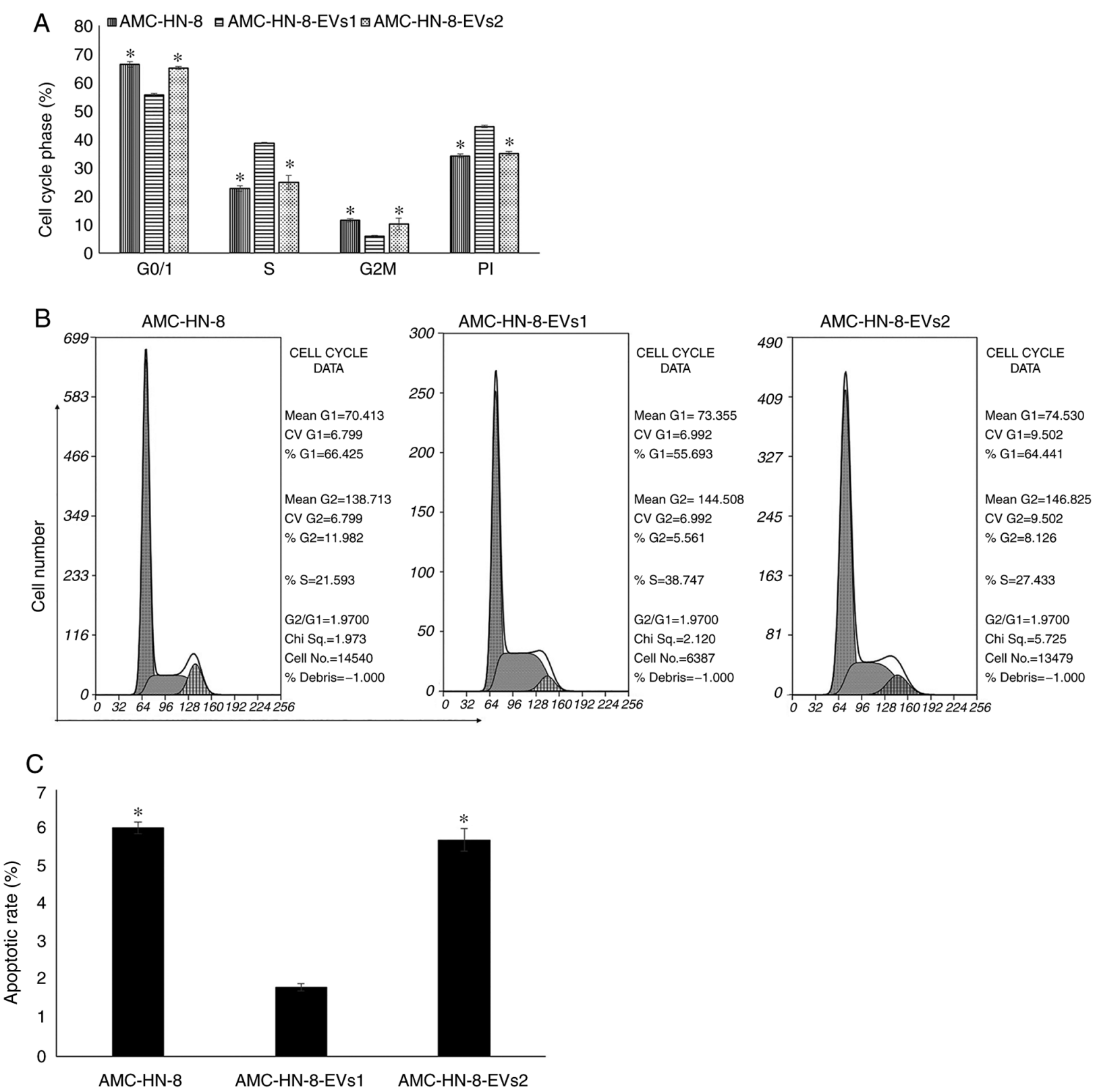

$\mathrm{D}$
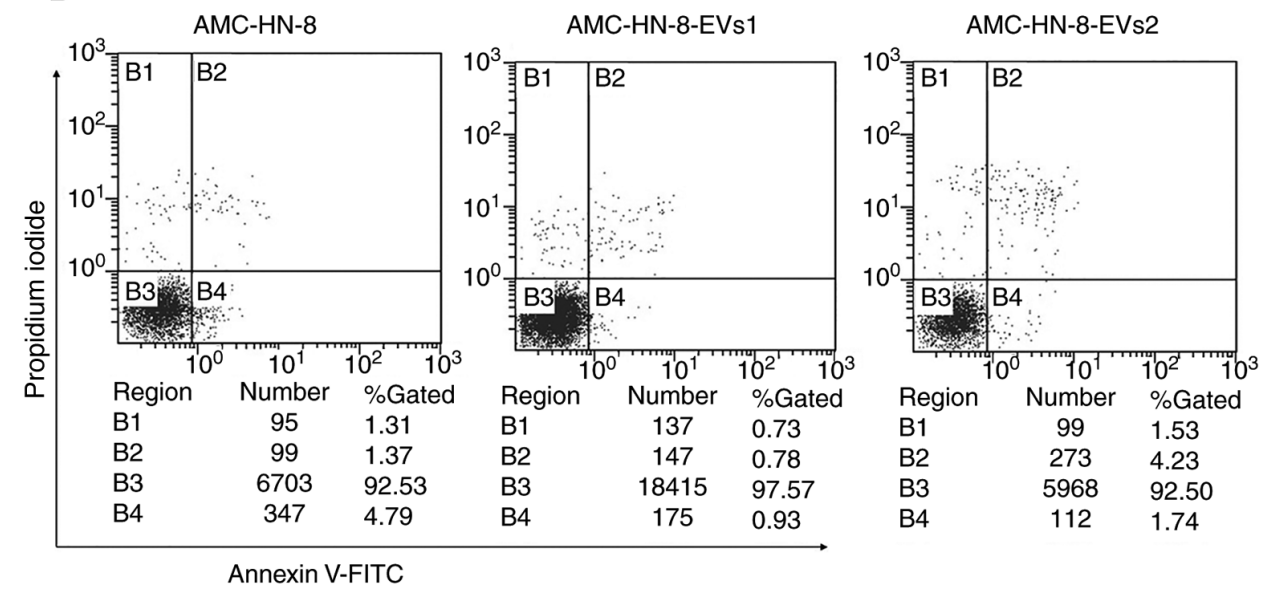

Figure 3. Cell cycle and apoptotic rate analysis of AMC-HN-8 cells following treatment with EVs. (A) The number of cell in the S phase and the cell PI were significantly higher in the AMC-HN-8-EVs1 group compared with those in the AMC-HN-8-EVs2 and control groups, whereas the numbers of cells in the $\mathrm{G}_{0 / 1}$ and $\mathrm{G}_{2} / \mathrm{M}$ phases were lower. (B) Representative flow cytometry plots of the cell cycle distribution of AMC-HN-8 cells following treatment with EVs. (C) Cells in the AMC-HN-8-EVs1 group exhibited a lower apoptotic rate compared with that in the AMC-HN-8-EVs2 and AMC-HN-8 groups. "P<0.01 vs. AMC-HN-8-EVs1. (D) Representative flow cytometry plots of AMC-HN-8 cells following 48-h treatment with EVs. ABCG2, ATP-binding transporter G2; CDDP, cisplatin; EVs, extracellular vehicles; EVs1, EVs derived from AMC-HN-8/CDDP cells; EVs2, EVs derived from AMC-HN-8 cells; PI, proliferation index. 


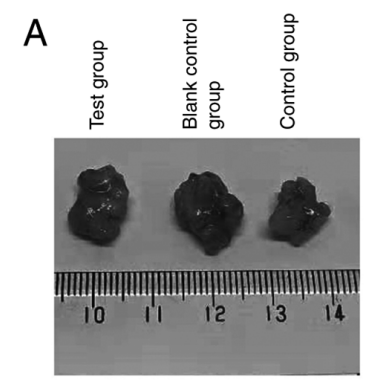

B

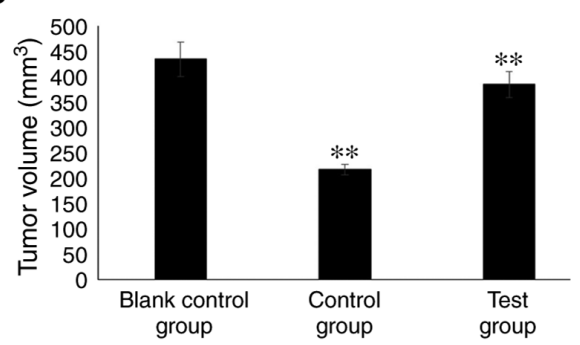

C

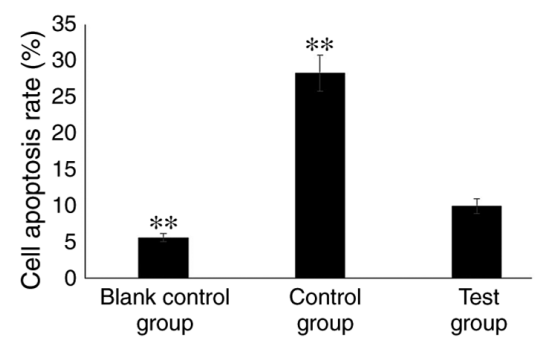

D

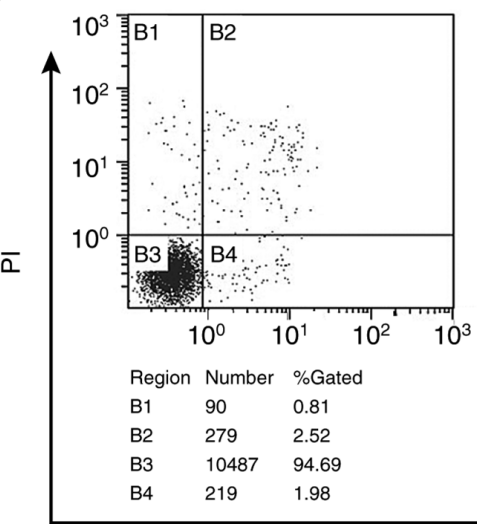

Control group

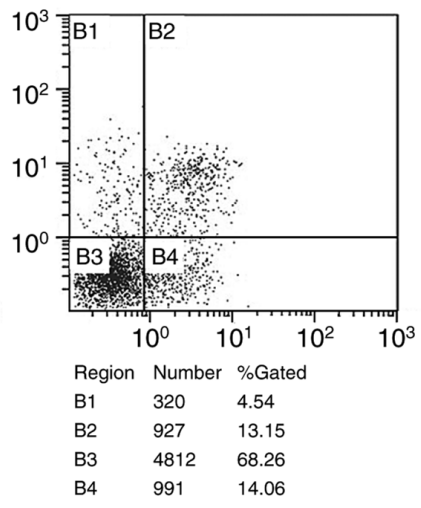

Test group

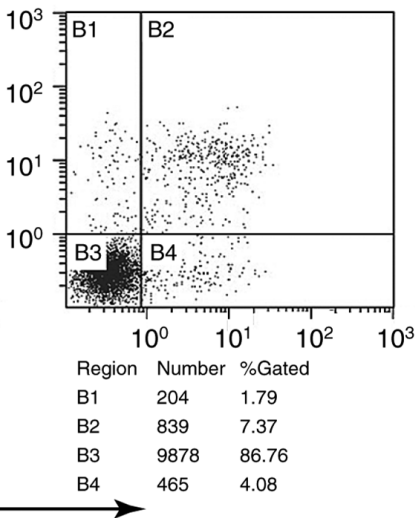

Region Number \%Gated

$204 \quad 1.79$

$\begin{array}{ll}-465 & 4.08\end{array}$

Annexin V-FITC

E

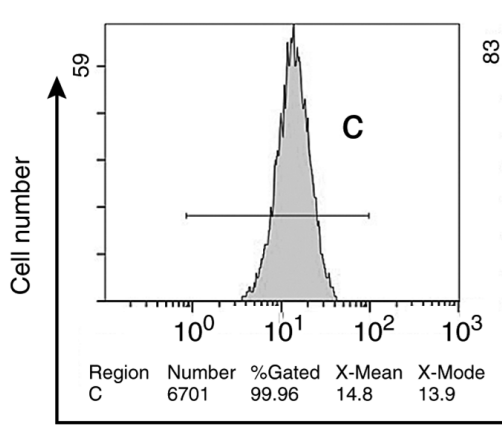

Blank control group

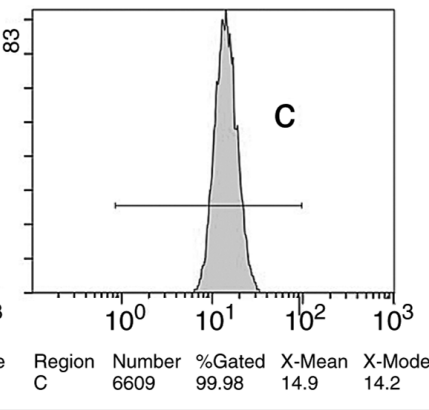

Test group

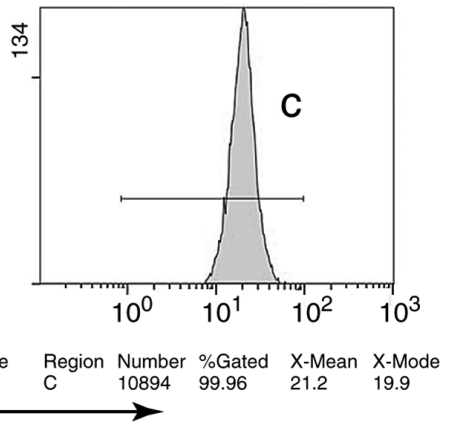

ABCG2 protein expression

F

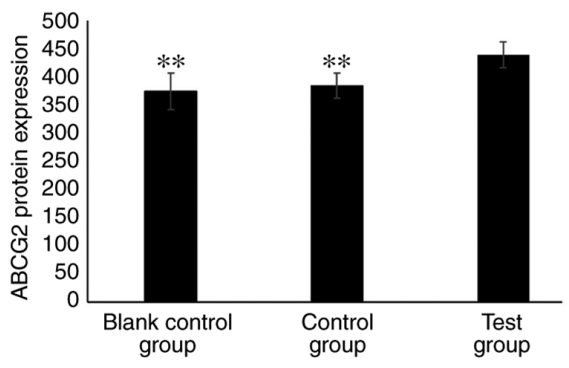

G

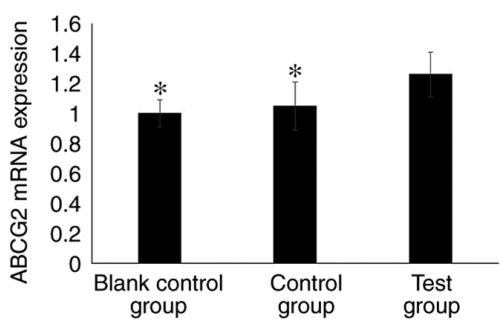

Figure 4. Drug-resistant phenotype of AMC-HN-8 cells is modulated by EVs in vivo. (A) Establishment of drug-resistant subcutaneous tumors in nude mice. (B) CDDP inhibits AMC-HN-8 and AMC-HN-8-EVs2 cell-derived tumor growth ( $\mathrm{n}=6$ ). Compared with that in the control group, the mean volume of subcutaneously implanted tumors in the test group was significantly higher. ${ }^{* *} \mathrm{P}<0.01$ vs. blank control group. (C and D) The apoptotic rates of tumor cells in nude mice. (C) The apoptotic rate of the test group was significantly lower compared with that in the control group and higher compared with that in the blank control group ** $\mathrm{P}<0.01$ vs. test group. (D) Representative flow cytometry plots of the apoptotic rates of subcutaneous tumor cells in nude mice following CDDP treatment. (E and F) ABCG2 protein expression in subcutaneously implanted tumor cells. (E) Representative flow cytometry plots of ABCG2 protein expression levels in subcutaneously implanted tumor cells following CDDP treatment. (F) The ABCG2 protein expression levels in the test group were significantly higher compared with those in the blank control and control groups. ${ }^{* *} \mathrm{P}<0.01$ vs. test group. (G) ABCG2 mRNA expression levels in subcutaneously implanted tumor cells following CDDP treatment determined by reverse transcription-quantitative PCR. The ABCG2 mRNA expression levels in the test group were significantly higher compared with those in the blank control and control groups. " $\mathrm{P}<0.05$ vs. test group. Blank control group, mice inoculated with AMC-HN-8 cells and intraperitoneally injected with normal saline; control group, mice inoculated with AMC-HN-8 cells and intraperitoneally injected with 3 mg/kg CDDP; test group, mice inoculated with AMC-HN-8-EVs1 cells and intraperitoneally injected with $3 \mathrm{mg} / \mathrm{kg}$ CDDP; ABCG2, ATP-binding transporter G2; CDDP, cisplatin; EVs, extracellular vehicles; EVs1, EVs derived from AMC-HN-8/CDDP cells; EVs2, EVs derived from AMC-HN-8 cells. 
no differences compared with the control group $(\mathrm{P}>0.05)$. In the $\mathrm{S}$ phase, the percentage of cells in the EVs1 group was higher compared with that in the EVs2 and control groups $(\mathrm{P}<0.01)$, and the EVs2 group exhibited no significant differences compared with the control group $(\mathrm{P}>0.05)$. The cell PI in the EVs1 group was higher compared with those in the EVs2 and control groups $(\mathrm{P}<0.01)$, whereas the EVs2 group exhibited no differences compared with the control group $(\mathrm{P}>0.05)$ (Fig. 3A and B).

The EVs1 group exhibited a lower apoptotic rate compared with that in the control and EVs2 groups $(\mathrm{P}<0.01)$. No significant differences were observed in the apoptotic rates between the EVs2 and control groups ( $\mathrm{P}>0.05)$ (Fig. 3C and D).

Drug-resistant phenotype of AMC-HN-8 cells is modulated by $E V s$ in vivo. The nude mouse xenografts models of human laryngeal carcinoma were successfully established. The tumors started to grow from day 5 post-inoculation of AMC-HN-8 and AMC-HN-8-EVs1 cells, and the tumor volume gradually increased with a tumor formation rate of $100 \%$ (Fig. 4A). The drug administration began after the tumors grew $>0.5 \mathrm{~cm}$.

Compared with that in the control group, the mean volume of the subcutaneously implanted tumors in the test group was significantly higher $(\mathrm{P}<0.01 ; \mathrm{Fig}$. 4B). In the control group, the volume inhibitory rate of CDDP on the growth of the subcutaneously implanted tumor was $50.06 \%$. In the test group, the volume inhibitory rate of CDDP on the growth of the subcutaneously implanted tumor was $11.41 \%$ (data not shown). Compared with those in the control group, the subcutaneously implanted tumor cells in the test group were resistant to CDDP.

The apoptotic rate of the cells isolated from the tumors in the test group was significantly lower compared with that in the cells from the control group, but significantly higher compared with that in the cells from the blank control group $(\mathrm{P}<0.01$; Fig. 4C and D).

The ABCG2 mRNA and protein expression levels in the test group were significantly higher compared with those in the blank control and control groups $(\mathrm{P}<0.01$; Fig. 4E-G).

\section{Discussion}

Chemotherapy is one of the main methods for the treatment of malignant tumors, especially for patients with late and postoperative recurrence (9). The main disadvantages of chemotherapy include the side effects of chemotherapy drugs and drug resistance $(38,39)$; drug resistance severely affects the efficacy of chemotherapy.

To date, the following major mechanisms of tumor drug resistance have been described: i) Drug efflux pump mediated by membrane transporters, where the level of antitumor drugs in multidrug-resistant cells is reduced through the drug pump function of transmembrane transporter (40); ii) enzymemediated resistance, where the activation of cell oxidation and the glutathione-related detoxification enzyme system result in direct inactivation of drugs or acceleration of drug excretion, e.g. by protein kinase $\mathrm{C}$ and glutathione transferase (41); and iii) apoptotic gene-mediated resistance, where p53 gene mutation reduces the expression levels of apoptotic genes and proteins, and increases the expression levels of antiapoptotic factors, such as Bcl-2, allowing multidrug-resistant cells to resist and escape the apoptosis induced by antitumor drugs (42). In particular, the mechanism of membrane transporter-mediated drug efflux pump has been thoroughly studied.

The ABC transporter family is associated with tumor drug resistance (43-45) and serves a role of drug efflux pump mediated by membrane transporters; ABC transporters reduce the effective drug concentration in cells and induce drug resistance $(46,47)$. For example, Hofman et al (46) have demonstrated that ABCG2 served as a drug (mitoxantrone) efflux transporter to induce drug resistance in A431 cells in vitro. Zhang et al (48) have demonstrated that ABCG2 mediates drug (mitoxantrone) resistance of colon cancer S1-M1-80 cells. Bar-Zeev et al (49) have reported that the drug (mitoxantrone) resistance of gastric cancer EPG85-257RNOV cells is mediated by ABCG2 and reversed by inhibiting the ABCG2-dependent efflux pumps. Ge et al (50) have demonstrated that high expression levels of ABCG2 mediate the drug (doxorubicin) resistance of lung cancer H460/MX20 cells and colorectal cancer S1-MI-80 cells. Baxter et al (51) have reported that ABCG2 is commonly and significantly upregulated in breast cancer following treatment with neoadjuvant endocrine therapy in three separate cohorts comprising a total of 200 patients, and ABCG2 upregulation is significantly associated with tumor chemoresistance.

In our previous study, ABCG2 was demonstrated to be abnormally highly expressed in esophageal cancer tissues and to be involved in the development of drug resistance in esophageal cancer (18). Laryngeal cancer is a common cancer of the head and neck, and determining the mechanism of drug resistance is of great significance to improve the therapeutic effects and the survival rate of patient with laryngeal cancer. To achieve this, in the present study, a CDDP-resistant laryngeal cancer cell line AMC-HN-8/CDDP was established by culture with increasing CDDP concentrations. The ABCG2 gene and protein expression levels in the AMC-HN-8/CDDP cells were significantly increased compared with those in the parental cells, suggesting that ABCG 2 may be involved in the development of drug resistance in laryngeal cancer. However, the absence of clinical data (e.g., expression levels in tissues and association with patient prognosis) is a limitation of the present study: In our future studies, clinical data will be used to verify the results.

EVs are bioactive substances secreted by cells; during the process of EV formation, the proteins, mRNAs and non-coding RNAs from the source cells are functionally selected and released into the target cells following interaction between EVs and target cells, and they serve a functional role by altering the phenotype and genotype of the target cells (31). The EVs in the tumor microenvironment regulate the biological characteristics of target cells, thus affecting their biological behavior (52). Previous studies have reported that the EVs in the tumor microenvironment regulate drug resistance of various types of tumor cells, such as breast cancer, glioma and lung cancer cells $(53,54)$. Wang et al $(55)$ have demonstrated that the chemotherapeutic drug vincristine stimulates drug-resistant KBv200 cells to release EVs containing ABCB1, which in turn lead to a significant increase of ABCB1 intercellular transfer to develop a drug-resistant phenotype. Bouvy et al (56) have reported that EVs from HL60/AR interact with HL60 cells and, at least partially, transfer their chemoresistance. Soekmadji et al (57) 
have reviewed that the role of EVs in mediating drug (mitoxantrone) resistance in prostate cancer cell PC3, particularly the role of EVs mediating drug resistance in advanced prostate cancer. Ma et al (58) have demonstrated that short transient receptor potential channel 5-containing circulating EVs may transfer the Adriamycin chemoresistance property to chemosensitive MCF-7/WT recipient cells. In our previous study, EVs with high expression levels of ABCG2 were demonstrated to regulate the drug resistance of esophageal cancer (59). In the present study, whether EVs released by drug-resistant cells may affect the drug resistance of their surrounding cells was studied in order to provide novel ideas for the study of drug resistance in laryngeal cancer. In vitro experiment results demonstrated that the ABCG2 expression levels in the EVs released by AMC-HN-8/CDDP cells were significantly increased compared with those in the EVs from AMC-HN-8 cells, suggesting that EVs may modulate the drug resistance of cells via ABCG2 present in EVs. Following treatment of the parental cells with EVs released by AMC-HN-8/CDDP cells, the parental cells exhibited drug resistance, decreased apoptotic rate and reduced cell proliferation compared with those cells in the control group or cells treated with EVs released by AMC-HN-8 cells, suggesting that exposure to EVs may affect cell drug resistance. To further verify the role of EVs with high levels of ABCG2 in the regulation of drug resistance, a subcutaneous tumor model of laryngeal cancer drug-resistant cells was established in the present study. The subcutaneously transplanted tumor was established by injecting laryngeal cancer cells treated with EVs with high levels of ABCG2. The results of the xenograft experiment demonstrated that the subcutaneously transplanted tumors of the test group (inoculated with AMC-HN-8-EVs1 cells) were resistant to CDDP, and $\mathrm{ABCG} 2$ was highly expressed in the cells isolated from the tumors. These results suggested that EVs may upregulate the expression levels of ABCG2 in the target cells, leading to drug resistance of the target cells.

The exact mechanism of action of ABCG2 in drug resistant cells regulating the drug resistance of the surrounding cells has not been elucidated to date. In the present study, the regulatory effects of EVs on the drug resistance of laryngeal cancer cells were explored. The absence of other laryngeal cancer cell lines and ABCG2-knockdown experiments were potential limitations of the present study; in future studies, additional laryngeal cancer cell lines and knockdown ABCG2 expression experiment should be used to verify the results.

In conclusion, the results of the present study demonstrated ABCG2 was involved in the drug resistance of laryngeal squamous cell carcinoma, and high expression levels of ABCG2 in EVs released by drug-resistant laryngeal cancer cells modulated the drug resistance of target cells. EVs with high levels of ABCG2 upregulated the expression of ABCG2 in the target cells, inducing drug resistance. The results of the present study suggested that drug-resistant laryngeal cancer cells may induce drug resistance by EVs released into the tumor microenvironment, providing an experimental basis to further study the drug resistance mechanism of laryngeal cancer. The molecular mechanisms underlying drug resistance modulated by EVs are complex, necessitating further study in the future. The function of ABCG2 in reducing the intracellular effective drug concentration will be analyzed in future experiments.

\section{Acknowledgements}

Not applicable.

\section{Funding}

No funding was received.

\section{Availability of data and materials}

The datasets used and/or analyzed during the present study are available from the corresponding author on reasonable request.

\section{Authors' contributions}

YZ performed the experiments and wrote the manuscript. YC and JW performed the experiments and statistical analysis. LL designed the study, performed the experiments and revised the manuscript. YZ and LL confirm the authenticity of all the raw data. All authors read and approved the final version of the manuscript.

\section{Ethics approval and consent to participate}

The Ethics Committee of the Fourth Hospital of Hebei Medical University (Shijiazhuang, China) approved this study (approval no. 2018MEC106).

\section{Patient consent for publication}

Not applicable.

\section{Competing interests}

The authors declare that they have no competing interests.

\section{References}

1. He Y, Liang D, Li D, Shan B, Zheng R, Zhang S, Wei W and He J: Incidence and mortality of laryngeal cancer in China, 2015. Chin J Cancer Res 32: 10-17, 2020.

2. Tang D, Tao L, Zhou L, Zhang M, Wu H, Li X, Chen X, Li C, Xie $\mathrm{M}$ and Cheng L: Retrospective analysis of 659 laryngeal squamous cell carcinoma patients treated with open laryngeal function-preserving operations. Acta Otolaryngol 138: 1043-1050, 2018

3. Zhou J, Zhou L, Tao L, Zhang M, Wu H, Chen X, Li X, Li C and Gong H: Oncological outcomes of surgical treatment for T3 supraglottic laryngeal squamous cell carcinoma patients. Acta Otolaryngol 138: 1028-1034, 2018.

4. Adeel M, Faisal M, Rashid A, Rasheed S, Hussain R, Malik KI, Hameed MY and Jamshed A: Outcomes of definitive radiotherapy for early laryngeal cancer in terms of survival and patterns of failure. J Laryngol Otol 133: 1087-1091, 2019.

5. Ozdemir Y and Topkan E: Second primary malignancies in laryngeal carcinoma patients treated with definitive radiotherapy. Indian J Cancer 56: 29-34, 2019.

6. Hsieh CH, Lin CY, Hsu CL, Fan KH, Huang SF, Liao CT, Lee LY, $\mathrm{Ng} \mathrm{SK}$, Yen TC, Chang JT, et al: Incorporation of Astragalus polysaccharides injection during concurrent chemoradiotherapy in advanced pharyngeal or laryngeal squamous cell carcinoma: Preliminary experience of a phase II double-blind, randomized trial. J Cancer Res Clin Oncol 146: 33-41, 2020.

7. Spector ME, Rosko AJ, Swiecicki PL, Chad Brenner J and Birkeland AC: From VA Larynx to the future of chemoselection: Defining the role of induction chemotherapy in larynx cancer. Oral Oncol 86: 200-205, 2018. 
8. Zeng H, Huang Y, Chen L, Li H and Ma X: Exploration and validation of the effects of robust co-expressed immune-related genes on immune infiltration patterns and prognosis in laryngeal cancer. Int Immunopharmacol 85: 106622, 2020.

9. Forastiere AA, Goepfert H, Maor M, Pajak TF, Weber R, Morrison W, Glisson B, Trotti A, Ridge JA, Chao C, et al: Concurrent chemotherapy and radiotherapy for organ preservation in advanced laryngeal cancer. N Engl J Med 349: 2091-2098, 2003.

10. Li R, Chen S, Zhan J, Li X, Liu W, Sheng X, Lu Z, Zhong R, Chen L, Luo X, et al: Long noncoding RNA FOXD2-AS1 enhances chemotherapeutic resistance of laryngeal squamous cell carcinoma via STAT3 activation. Cell Death Dis 11: 41, 2020.

11. Zhu M, Yin F, Yang L, Chen S, Chen R, Zhou X, Jing W, Fan X, Jia R, Wang H, et al: Contribution of TIP30 to chemoresistance in laryngeal carcinoma. Cell Death Dis 5: e1468, 2014.

12. Gottesman MM, Fojo T and Bates SE: Multidrug resistance in cancer: Role of ATP-dependent transporters. Nat Rev Cancer 2: 48-58, 2002.

13. Feng SL, Luo HB, Cai L, Zhang J, Wang D, Chen YJ, Zhan HX, Jiang ZH and Xie Y: Ginsenoside Rg5 overcomes chemotherapeutic multidrug resistance mediated by ABCB1 transporter: In vitro and in vivo study. J Ginseng Res 44: 247-257, 2020.

14. Ke B, Wei T, Huang Y, Gong Y, Wu G, Liu J, Chen X and Shi L: Interleukin-7 Resensitizes Non-Small-Cell Lung Cancer to Cisplatin via Inhibition of ABCG2. Mediators Inflamm 2019: 7241418, 2019

15. Sinha BK, Perera L and Cannon RE: Reversal of drug resistance by JS-K and nitric oxide in ABCB1- and ABCG2-expressing multi-drug resistant human tumor cells. Biomed Pharmacother 120: 109468, 2019

16. Xie ZY, Wang FF, Xiao ZH, Liu SF, Tang SL and Lai YL: Overexpressing microRNA-34a overcomes ABCG2-mediated drug resistance to 5-FU in side population cells from colon cancer via suppressing DLL1. J Biochem 167: 557-564, 2020.

17. Liu L, Zuo LF and Guo JW: ABCG2 gene amplification and expression in esophageal cancer cells with acquired adriamycin resistance. Mol Med Rep 9: 1299-1304, 2014.

18. Wang L, Liu L, Chen Y, Du Y, Wang J and Liu J: Correlation between adenosine triphosphate (ATP)-binding cassette transporter G2 (ABCG2) and drug resistance of esophageal cancer and reversal of drug resistance by artesunate. Pathol Res Pract 214: 1467-1473, 2018

19. He M, Wu H, Jiang Q, Liu Y, Han L, Yan Y, Wei B, Liu F, Deng X, Chen $\mathrm{H}$, et al: Hypoxia-inducible factor- $\alpha \alpha$ directly promotes BCRP expression and mediates the resistance of ovarian cancer stem cells to adriamycin. Mol Oncol 13: 403-421, 2019.

20. Kim CK, Oh S, Kim SJ, Leem SH, Heo J and Chung SH: Correlation of IGF1R expression with ABCG2 and CD44 expressions in human osteosarcoma. Genes Genomics 40 : 381-388, 2018

21. Liang YL, Wu CH, Kang CY, Lin CN, Shih NY, Lin SH, Chen YC and Hsu KF: Downregulated Salt-inducible Kinase 3 Expression Promotes Chemoresistance in Serous Ovarian Cancer via the ATP-binding Cassette Protein ABCG2. J Cancer 10: 6025-6036, 2019.

22. Das S, Mukherjee P, Chatterjee R, Jamal Z and Chatterji U: Enhancing Chemosensitivity of Breast Cancer Stem Cells by Downregulating SOX2 and ABCG2 Using Wedelolactoneencapsulated Nanoparticles. Mol Cancer Ther 18: 680-692, 2019.

23. Shen B, Dong P, Li D and Gao S: Expression and function of ABCG2 in head and neck squamous cell carcinoma and cell lines. Exp Ther Med 2: 1151-1157, 2011.

24. Denton AE, Roberts EW and Fearon DT: Stromal Cells in the Tumor Microenvironment. Adv Exp Med Biol 1060: 99-114, 2018.

25. Wu T and Dai Y: Tumor microenvironment and therapeutic response. Cancer Lett 387: 61-68, 2017.

26. Akhtar M, Haider A, Rashid S and Al-Nabet ADMH: Paget's 'Seed and Soil' Theory of Cancer Metastasis: An Idea Whose Time has Come. Adv Anat Pathol 26: 69-74, 2019.

27. Hayashida T, Jinno H and Kitagawa Y: Epithelial-mesenchymal transition and tumor microenvironment propose the seed and soil theory of the present age. Nihon Rinsho 70 (Suppl 7): 203-207, 2012 (In Japanese).

28. Mulcahy LA, Pink RC and Carter DR: Routes and mechanisms of extracellular vesicle uptake. J Extracell Vesicles: Aug 4, 2014. doi: $10.3402 /$ jev.v3.24641.
29. Haraszti RA, Didiot MC, Sapp E, Leszyk J, Shaffer SA, Rockwell HE, Gao F, Narain NR, DiFiglia M, Kiebish MA, et al: High-resolution proteomic and lipidomic analysis of exosomes and microvesicles from different cell sources. J Extracell Vesicles 5: $32570,2016$.

30. Lawson C, Vicencio JM, Yellon DM and Davidson SM: Microvesicles and exosomes: New players in metabolic and cardiovascular disease. J Endocrinol 228: R57-R71, 2016.

31. Becker A, Thakur BK, Weiss JM, Kim HS, Peinado H and Lyden D: Extracellular vesicles in cancer: Cell-to-cell mediators of metastasis. Cancer Cell 30: 836-848, 2016.

32. Lindenbergh MFS and Stoorvogel W: Antigen presentation by extracellular vesicles from professional antigen-presenting cells. Annu Rev Immunol 36: 435-459, 2018.

33. Joncas FH, Lucien F, Rouleau M, Morin F, Leong HS, Pouliot F, Fradet Y, Gilbert C and Toren P: Plasma extracellular vesicles as phenotypic biomarkers in prostate cancer patients. Prostate 79: 1767-1776, 2019.

34. Wang Y, Dong L, Zhong H, Yang L, Li Q, Su C, Gu W and Qian Y: Extracellular vesicles (EVs) from lung adenocarcinoma cells promote human umbilical vein endothelial cell (HUVEC) angiogenesis through yes kinase-associated protein (YAP) transport. Int J Biol Sci 15: 2110-2118, 2019.

35. Takahashi K, Yan IK, Wood J, Haga H and Patel T: Involvement of extracellular vesicle long noncoding RNA (linc-VLDLR) in tumor cell responses to chemotherapy. Mol Cancer Res 12: 1377-1387, 2014.

36. Zhou T, Li Y, Yang L, Liu L, Ju Y and Li C: Silencing of ANXA3 expression by RNA interference inhibits the proliferation and invasion of breast cancer cells. Oncol Rep 37: 388-398, 2017.

37. Livak KJ and Schmittgen TD: Analysis of relative gene expression data using real-time quantitative PCR and the 2(-Delta Delta C(T)) Method. Methods 25: 402-408, 2001.

38. Leung HW, Lau EYT, Leung CON, Lei MML, Mok EHK, Ma VWS, Cho WCS, Ng IOL, Yun JP, Cai SH, et al: NRF2/ SHH signaling cascade promotes tumor-initiating cell lineage and drug resistance in hepatocellular carcinoma. Cancer Lett 476: 48-56, 2020

39. Zhong P, Chen X, Guo R, Chen X, Chen Z, Wei C, Li Y, Wang W, Zhou Y and Qin L: Folic acid-modified nanoerythrocyte for codelivery of paclitaxel and tariquidar to overcome breast cancer multidrug resistance. Mol Pharm 17: 1114-1126, 2020.

40. Paškevičiūtė $M$ and Petrikaitė $V$ : Overcoming transportermediated multidrug resistance in cancer: Failures and achievements of the last decades. Drug Deliv Transl Res 9: 379-393, 2019.

41. Ganapathi RN and Ganapathi MK: Mechanisms regulating resistance to inhibitors of topoisomerase II. Front Pharmacol 4: 89, 2013.

42. Nagraj J, Chatterjee S, Pal T, Sakpal AS, Gota V, Ramaa CS and Ray P: A novel series of di-fluorinated propanedione derivatives synergistically augment paclitaxel mediated caspase 3 activation in ovarian cancer cells. J Cancer Res Ther 10: 701-709, 2014.

43. Ambjorner SEB, Wiese M, Kohler SC, Svindt J, Lund XL, Gajhede M, Saaby L, Brodin B, Rump S, Weigt H, et al: The pyrazolo[3,4-d]pyrimidine derivative, SCO-201, reverses multidrug resistance mediated by ABCG2/BCRP. Cells 9: 613, 2020.

44. Gao Q, Li XX, Xu YM, Zhang JZ, Rong SD, Qin YQ and Fang J: IRE1 $\alpha$-targeting downregulates ABC transporters and overcomes drug resistance of colon cancer cells. Cancer Lett 476: 67-74, 2020.

45. Wu CP, Lusvarghi S, Tseng PJ, Hsiao SH, Huang YH, Hung TH and Ambudkar SV: MY-5445, a phosphodiesterase type 5 inhibitor, resensitizes ABCG2-overexpressing multidrugresistant cancer cells to cytotoxic anticancer drugs. Am J Cancer Res 10: 164-178, 2020.

46. Hofman J, Sorf A, Vagiannis D, Sucha S, Kammerer S, Küpper JH, Chen S, Guo L, Ceckova M and Staud F: Brivanib exhibits potential for pharmacokinetic drug-drug interactions and the modulation of multidrug resistance through the inhibition of human ABCG2 drug efflux transporter and CYP450 biotransformation enzymes. Mol Pharm 16: 4436-4450, 2019.

47. Bhardwaj B, Baidya ATK, Amin SA, Adhikari N, Jha T and Gayen S: Insight into structural features of phenyltetrazole derivatives as ABCG2 inhibitors for the treatment of multidrug resistance in cancer. SAR QSAR Environ Res 30: 457-475, 2019.

48. Zhang YK, Wang YJ, Lei ZN, Zhang GN, Zhang XY, Wang DS, Al-Rihani SB, Shukla S, Ambudkar SV, Kaddoumi A, et al: Regorafenib antagonizes BCRP-mediated multidrug resistance in colon cancer. Cancer Lett 442: 104-112, 2019. 
49. Bar-Zeev M, Kelmansky D, Assaraf YG and Livney YD $\beta$-Casein micelles for oral delivery of SN-38 and elacridar to overcome BCRP-mediated multidrug resistance in gastric cancer. Eur J Pharm Biopharm 133: 240-249, 2018.

50. Ge C, Wang F, Cui C, Su X, To KKW, Wang X, Zhang H, Song X and Fu L: PCI29732, a Bruton's tyrosine kinase inhibitor, enhanced the efficacy of conventional chemotherapeutic agents in ABCG2-overexpressing cancer cells. Cell Physiol Biochem 48: 2302-2317, 2018

51. Baxter DE, Kim B, Hanby AM, Verghese ET, Sims AH and Hughes TA: Neoadjuvant endocrine therapy in breast cancer upregulates the cytotoxic drug pump $\mathrm{ABCG} 2 / \mathrm{BCRP}$, and may lead to resistance to subsequent chemotherapy. Clin Breast Cancer 18: 481-488, 2018.

52. Tkach $\mathrm{M}$ and Théry $\mathrm{C}$ : Communication by extracellular vesicles: Where we are and where we need to go. Cell 164: 1226-1232, 2016.

53. Han L, Lam EW and Sun Y: Extracellular vesicles in the tumor microenvironment: Old stories, but new tales. Mol Cancer 18: 59, 2019.

54. Yousafzai NA, Wang $\mathrm{H}$, Wang Z, Zhu Y, Zhu L, Jin H and Wang X: Exosome mediated multidrug resistance in cancer. Am J Cancer Res 8: 2210-2226, 2018.
55. Wang X, Qiao D, Chen L, Xu M, Chen S, Huang L, Wang F, Chen Z, Cai J and Fu L: Chemotherapeutic drugs stimulate the release and recycling of extracellular vesicles to assist cancer cells in developing an urgent chemoresistance. Mol Cancer 18: $182,2019$.

56. Bouvy C, Wannez A, Laloy J, Chatelain C and Dogné JM: Transfer of multidrug resistance among acute myeloid leukemia cells via extracellular vesicles and their microRNA cargo. Leuk Res 62: 70-76, 2017.

57. Soekmadji $\mathrm{C}$ and Nelson CC: The emerging role of extracellular vesicle-mediated drug resistance in cancers: Implications in advanced prostate cancer. BioMed Res Int 2015: 454837, 2015.

58. Ma X, Chen Z, Hua D, He D, Wang L, Zhang P, Wang J, Cai Y, Gao C, Zhang X, et al: Essential role for TrpC5-containing extracellular vesicles in breast cancer with chemotherapeutic resistance. Proc Natl Acad Sci USA 111: 6389-6394, 2014

59. Chen Y, Liu L, Li J, Du Y, Wang J and Liu J: Effects of long noncoding RNA (linc-VLDLR) existing in extracellular vesicles on the occurrence and multidrug resistance of esophageal cancer cells. Pathol Res Pract 215: 470-477, 2019. 